\title{
TECHNICAL NOTE: ‘CUT AND SEW' TECHNIQUE IN THE RESECTION OF ESOPHAGOGASTRIC JUNCTION TUMOURS VIA TRANSABDOMINAL APPROACH ALONE
}

\author{
Engin HATIPOGLU ${ }^{1}$, Metin ERTEM ${ }^{1}$, Sabri ERGUNEY ${ }^{1}$ \\ ${ }^{1}$ Department of General Surgery, Istanbul University, Cerrahpasa Medical School, Turkey
}

Received 24 Jan 2020, Corrections received 20 Febr 2020, Accepted 29 Apr 2020

https://doi.org/10.31688/ABMU.2020.55.2.23

\begin{abstract}
Introduction. In the surgery of esophagogastric junction tumours, obtaining a tumour-free proximal surgical margin and determining the right approach to reach this goal may be challenging.

The objective of the study was to make a technical contribution to the performance of high esophago-jejunal anastomoses via transabdominal approach alone, following resection of esophagogastric junction tumours. We named this technique as the „cut and sew" technique.

Material and methods. Between January 2015 and December 2017, 113 patients were operated with curative intent for gastric cancer in our surgical unit. Distal gastrectomy was performed in 41 patients, while $51 \mathrm{pa}-$ tients underwent total gastrectomy. The remaining 21 patients, who constitute the subjects of this study, presented with a Siewert type II (8 patients) or a Siewert type III (13 patients) esophagogastric junction tumour. Results. One patient in the neoadjuvant chemoradiotherapy group, with additional thoracotomy, died because of pulmonary complications and respiratory failure. No mortality or any significant morbidity was seen in the group operated transabdominally alone.
\end{abstract}

Résumé

Note technique : la technique " cut and sew « dans la résection des tumeurs de la jonction gastro-oesophagienne par seule la voie abdominale

Introduction. Dans la chirurgie de la jonction gastro-oesophagienne, obtenir une marge chirurgicale proximale saine et déterminer la voie d'abord adéquate dans ce but, peut constituer un problème.

Le but de l'étude est d'apporter une contribution technique à la performance d'anastomoses oesophago-jéjunales à la suite de résections des tumeurs de la jonction gastro-oesophagienne.

Matériel et méthode. Entre Janvier 2015 et Décembre 2017, 113 malades ont été opérés à intention curative pour cancer de l'estomac dans notre service. 41 gastrectomies distales et 51 gastrectomies totales ont été effectuées. Le reste de 21 malades qui forment le sujet de l'article, se sont adressés pour tumeur de la jonction gastro-oesophagienne, dont 8 avec une tumeur de type Siewert 2 et 13 avec tumeur de type Siewert 3.

Résultats. Un malade ayant subi une chimiothérapie préopératoire et ayant nécessité une thoracotomie, est 
Conclusions. The „cut and sew“ technique is efficient and safe in performing high esophago-jejunal anastomosis following resection of Siewert type 2 and 3 esophagogastric junction tumours, through abdominal approach alone. The omission of an additional thoracic route decreases the morbidity and eventually the mortality.

Keywords: esophagogastric junction tumours, high esophago-jejunal anastomosis, technical contribution.

\section{INTRODUCTION}

Esophagogastric junction tumours are observed more frequently, possibly because of the increasing frequency of Barrett's metaplasia ${ }^{1,2}$.

Siewert divided the tumours of this area into three groups: type I (tumours that have a proximal margin within 1 to $5 \mathrm{~cm}$ from the gastroesophageal junction), type II (tumours located between $1 \mathrm{~cm}$ proximal and $2 \mathrm{~cm}$ distal to the gastroesophageal junction), type III (tumours situated 2 to $5 \mathrm{~cm}$ distal to the gastroesophageal junction) $)^{3}$. Thoracic approach is mandatory in Siewert type I tumors. For type III and particularly type II tumours, ensuring a tumor-free esophageal margin via transabdominal route alone is not always possible ${ }^{4}$. Although the use of circular staplers solved this problem by allowing access to more proximal "secure“ esophageal segments, there are still difficulties. During the placement of the anvil, or of the purse string suture, the esophageal margin can retract to the mediastinum due to slipping of the bowel clamp or tearing of the hanging sutures $^{5}$. This unfortunate incident may mandate an additional thoracic approach.

\section{Technique}

In order to prevent such occurrences, we present a simple and feasible technique that reduces the possibility for the need of an additional thoracotomy, while also allowing the establishment of a negative surgical margin by using the transabdominal approach alone.

Instead of transecting the esophagus in one step and placing the purse string sutures afterwards, we begin to place the purse string suture step by step, just when we begin to transect the esophagus, hence the name of the technique (Fig. 1, step 1). With this simple modification, the esophageal continuity is not décédé due à des complications et à une insuffisance respiratoire. Aucune mortalité n'a été notée chez les patients opérés par voie abdominale.

Conclusions. La technique " cut and sew " est efficace et sure dans la réalisation d'anastomoses oesophago-jéjunales hautes à la suite de résections des tumeurs de la jonction gastro-oesophagienne de type Siewert 2 et 3 , par voie d'abord abdominal. Le fait d'éviter une voie d'abord thoracique supplémentaire, baisse la morbidité et éventuellement la mortalité.

Mots-clés: tumeur de la jonction gastro-oesophagienne, anastomose oesophago-jéjunale haute, contribution technique.

disrupted until its whole perimeter is completely secured with the purse suture (Fig. 1, step 2).

\section{Material ANd methods}

Informed consent was obtained from all individual participants included in the study. All procedures performed in studies involving human participants were in accordance with the ethical standards of the institutional committee and with the 1975 Helsinki declaration and its later amendments or comparable ethical standards.

Among 21 patients with Siewert type II and III lesions, three could be operated through a single abdominal approach. These three patients, due to having a positive proximal (esophageal) surgical margin on frozen section biopsy, required an additional right thoracotomy and esophageal resection to obtain a safe surgical margin.

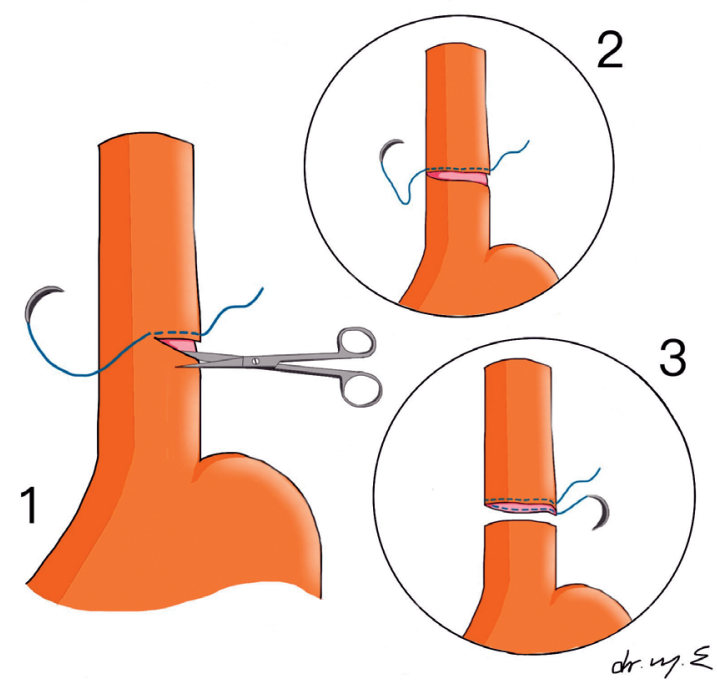

Figure 1 
Overall, the mean age of the study group was 59.2 years (range 42.74 years) and 17 of them were male. Seven patients received chemoradiotherapy and four received only chemotherapy before undergoing the operation.

\section{RESULTS}

One patient in the neoadjuvant chemoradiotherapy group, with additional thoracotomy, died because of pulmonary complications and respiratory failure. No mortality was seen in the group who underwent the transabdominal approach alone $(n=17)$.

Anastomotic leakage occurred in 2 patients operated via laparotomy alone and was treated conservatively (simple drainage in one and stent application in the other). These patients had not received neoadjuvant therapy. The mean distance of the microscopic tumor margin to the proximal specimen margin was $7.9 \mathrm{~mm}$ (range $5-20 \mathrm{~mm}$, median $7 \mathrm{~mm}$ ). In one patient, the definitive histopathological exam reported a positive surgical margin contrary to the frozen section report. He received adjuvant radio-chemotherapy. Fortunately, he is tumour-free 48 months after the initial surgical treatment. An anastomotic recurrence occurred in one patient 9 months after treatment, and the patient died at the $16^{\text {th }}$ month with peritoneal and hepatic metastases. The disease-free survival of patients was 21.9 months (range 6-24 months) and the mean overall survival was 28.15 months (range 9-40 months).

\section{Discussion}

From January 2015 to December 2017, we performed 21 total gastrectomy + distal esophagectomy procedures for Siewert type II and III (8 Siewert type II and 13 Siewert type III) gastroesophageal junction tumors. We applied the 'cut and sew' technique in all these cases. Right thoracotomy was required only in three patients due to the inability to obtain a secure surgical margin as demonstrated by frozen section biopsy. In the postoperative period, one leakage from the Siewert type III group and one leakage from the Siewert type 2 group were observed. They were treated conservatively, one with simple drainage and the other with the application of a trans-anastomotic stent.
This technique that is used with the transabdominal approach reduces the eventual need for an additional thoracotomy in Siewert type III and particularly in type II gastroesophageal junction tumors, while also allowing the establishment of a negative surgical margin.

\section{Author Contributions:}

Conceptualization, E.H.,S.E.; methodology, E.H.,M.E.,S.E.; software, E.H.,S.E.; validation, E.H.; formal analysis, E.H; investigation, E.H; resources, E.H.; data curation, E.H.,S.E.; writing-original draft preparation, E.H.,S.E.; writing-review and editing, E.H.,M.E.,S.E.; visualization, M.E.; supervision, M.E.,S.E.; project administration, E.H. All the authors have read and agreed with the final version of the article.

\section{Compliance with Ethics Requirements:}

„The authors declare no conflict of interest regarding this article"

"The authors declare that all the procedures and experiments of this study respect the ethical standards in the Helsinki Declaration of 1975, as revised in 2008(5), as well as the national law. Informed consent was obtained from all the patients included in the study"

"No funding for this study"

\section{Acknowledgments:}

None

\section{References}

1. Lochman P, Dušek T, Páral J. Esophagogastric junction and its tumours - comments to definition and classification. Casopis Lekaru Ceskych. 2018;157(2):84-89.

2. Sayin SI, Baumeister T, Wang TC, Quante M. Origins of metaplasia in the esophagus: is this a GE junction stem cell disease? Digestive Diseases and Sciences. 2018;63(8):2013-2021.

3. Siewert JR, Stein HJ. Classification of adenocarcinoma of the oesophagogastric junction. The British Journal of Surgery. 1998;85(11):1457-1459.

4. Mine S, Sano T, Hiki N, et al. Proximal margin length with transhiatal gastrectomy for Siewert type II and III adenocarcinomas of the oesophagogastric junction. The British Journal of Surgery. 2013;100(8):1050-1054.

5. Seshadri RA, Thammaiah SK, Vaidhyalingam V. Modified technique of stapled esophagojejunostomy without a purse-string suture. Indian Journal of Surgical Oncology. 2011;2(3):189-192. 